\title{
CPW-Fed Circular Polarized Square Slot Antenna for GPS Applications
}

\author{
Neda Rojhani ${ }^{\# 1}$, Samineh Sarbazi Golazari ${ }^{* 2}$, Nasrin Amiri ${ }^{* 2}$, Farrokh Hojjat Kashani ${ }^{3}$ \\ \# Department of Information Engineering \\ University of Florence, via Santa Marta, Firenze, Italy \\ ${ }^{1}$ neda.rojhani@unifi.it \\ ${ }^{2 *}$ Faculty of Engineering \\ South Tehran Branch, IAU,Tehran, Iran \\ ${ }^{3}$ Iran University of Science and Technology, Iran
}

\begin{abstract}
This study presents a design of a circular polarized square slot antenna (CPSSA) with a coplanar waveguide (CPW) for global positioning system (GPS) applications. The proposed antenna is composed of rectangular metal frame acting as a ground, two metal defected square rings at the back of the antenna and feed strip of CPW with an L-shaped. The GPS frequency of $1.57 \mathrm{GHz}$ can be obtained by setting the corresponding parameters. The designed antenna has a small size of $56 \times 56 \times 0.8 \mathrm{~mm}^{3}$. The simulated impedance bandwidth of the proposed antenna is $220 \mathrm{MHz}$ from 1.54 to $1.76 \mathrm{GHz}$ for VSWR less than 2 , and the axial ratio (AR) bandwidth is $75 \mathrm{MHz}$ less than $3 \mathrm{~dB}$ from 1.525 to $1.6 \mathrm{GHz}$, which appropriate the GPS L1 band requirement. Meanwhile, the radiation pattern is a bidirectional pattern with a maximum antenna gain of around $\mathbf{- 3 . 9} \mathrm{dB}$. The antenna can be used for GPS applications adopting circular polarization.
\end{abstract}

Index Terms - Axial Ratio (AR); coplanar waveguide $(C P W)$; Circulary Polarized (CP); GPS band; Square slot Antenna.

\section{INTRODUCTION}

Using Global Positioning System (GPS) technology is becoming more popular. GPS system has been extensively utilized as a navigation system to identify positions, survey and detect various devices [1]. Circular polarization (CP) is common polarization in mobile satellite communication as well as communication systems which is designed for allowable flexibility in transmission and receiver. The purpose of this design is preventing the polarization mismatch between transmitter and receiver owning to multipath fading in the propagation environments [2]. It is true that one of the most important goals of antenna designer, from designing large size antennas operating in law frequency like horn antennas to small size antennas working in high frequency like on chip antennas, with considering the enhance antenna efficiency is to reduce the size of antenna. In order to achieve this goal different kinds of methods such as Defected Ground Structure (DGS), Electromagnetic Band Gap (EBG) or also different materials like ionize gas antenna are studied by researchers [3-5]. In this paper, a planar waveguide (CPW) antenna has enjoyed a significant consideration due to their low cost, light weight, easy fabrication, wide bandwidths and CP operation; however, by employing different methods, like modified ground structure in terms of improving bandwidth and creating band notch to avoid interference among several applications these kinds of antennas can be enhanced in radiation features for various types of applications simultaneously [6-8]. The GPS antenna operates at the two GPS frequencies (L1: $1.575 \mathrm{GHz}, \mathrm{L} 2: 1.227 \mathrm{GHz}$ ). Several kinds of microstrip antennas with various feeding network systems for dual-band circular polarization GPS antennas have been introduced in [9]. Wang et al. have suggested double layers of the truncated square patch with air gap between the substrates in [10]. An aperture-coupled stacked microstrip antenna with cross-slot feed by David and Sean have been investigated in [11]. The multilayer substrate using high dielectric constant material was suggested by Chen et al in [12].

In this study, a new design of a CPW-feed square slot antenna with CP polarization is introduced for the GPS systems at $1.57 \mathrm{GHz}$. The suggested antenna occupies a compact size of $56 \times 56 \times 0.8 \mathrm{~mm}^{3}$. Such an antenna is simulated by means of Ansoft simulation software HighFrequency Structure Simulator (HFSS-v.15) based on the finite element method (FEM).

\section{ANTENNA CONFIGURATION}

The schematic of the proposed antenna is exhibited in Fig. 1. It is mounted on an economical plane of FR4 with dielectric constant $=4.4$, thickness $=0.8 \mathrm{~mm}$ and loss tangent $=0.02$. The overall dimensions of the antenna substrate are $56 \times 56 \mathrm{~mm}^{2}$ which were square with a lateral length Ls. The antenna is fed by a $50 \Omega$ an L-shaped CPW with width $3 \mathrm{~mm}$ for generating circular polarization. On the back of the antenna, two metal defected square rings are loaded which leads to achieve an acceptable impedance bandwidth. The detail dimensions of antenna in Fig. 1, are listed in table I. The antenna design procedure will be discussed in the next section. 
TABLE I

Proposed Antenna Dimensions in $\mathrm{mm}$

\begin{tabular}{|c|c|c|c|}
\hline Parameter & amount & Parameter & amount \\
\hline $\mathrm{Ls}$ & 56 & $\mathrm{~g}_{2}$ & 1 \\
\hline $\mathrm{G}$ & 39.4 & $\mathrm{r}_{1}$ & 5 \\
\hline $\mathrm{Lf}_{1}$ & 35.5 & $\mathrm{r}_{2}$ & 12.7 \\
\hline $\mathrm{Lf}_{2}$ & 29.5 & $\mathrm{~S}_{1}$ & 1.3 \\
\hline $\mathrm{Ws}$ & 3 & $\mathrm{~S}_{2}$ & 1.6 \\
\hline $\mathrm{g}_{1}$ & 1.6 & & \\
\hline
\end{tabular}

\section{ANTENNA PERFORMANCE AND DISCUSSION}

The proposed square slot antenna is simulated by using ANSYS High-Frequency Structural Simulator Software (HFSS). In Fig.2, four improved structures of the suggested antenna are shown for demonstrating the design process.

Ant I. is composed of only a rectangular metal frame acting as a ground and a feed line which has allowable impedance bandwidth for $1.54 \mathrm{GHz}$; In Ant II, a metal defected square is loaded on the back of the antenna which aims to attain an acceptable impedance bandwidth but the axial ratio bandwidth is over than $3 \mathrm{~dB}$. In this stage at Ant III, for producing the dual-band CP radiation, the feed line is changed to an L-shaped feed strip of CPW to support two perpendicular modes with equal magnitude and a 90 degrees phase difference. Finally, in Ant IV, for frequency shifting to have less than $-10 \mathrm{~dB}$ return loss impedance and $3 \mathrm{~dB}$ axial ratio bandwidths in width, the second metal defected square ring is loaded at the back of the antenna. Fig. 3, and Fig. 4, show simulated return loss and $3 \mathrm{~dB}$ axial ratio alterations in four antenna design stages. With regard to the Fig. 4a, it can be seen that Ant I. and Ant II, have a linear polarization. The AR is considerably improved by transforming the feed line to an L-shaped feed strip CPW (Ant III). At last, by exploiting the second metal defected square ring, the suggested antenna not only is exhibited the desired axial ratio bandwidth (ARBW $<3 \mathrm{~dB}$ ) from 1.525 to $1.6 \mathrm{GHz}$ but also enjoys a $-10 \mathrm{~dB}$ reflection coefficient bandwidth from 1.54 to $1.76 \mathrm{GHz}$ to cover the L1 GPS band.

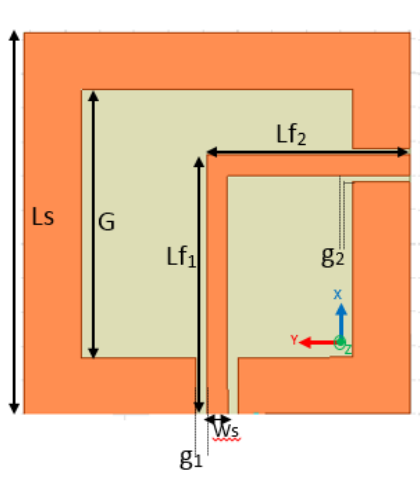

a) Top View

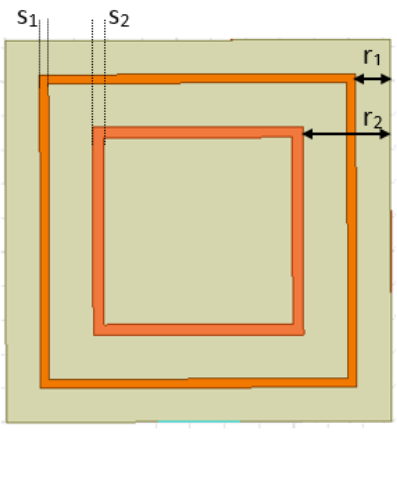

b) Back View
Fig 1.The shape of the proposed antenna

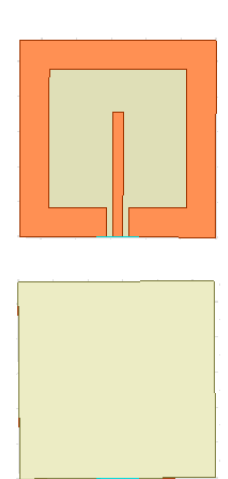

Ant I
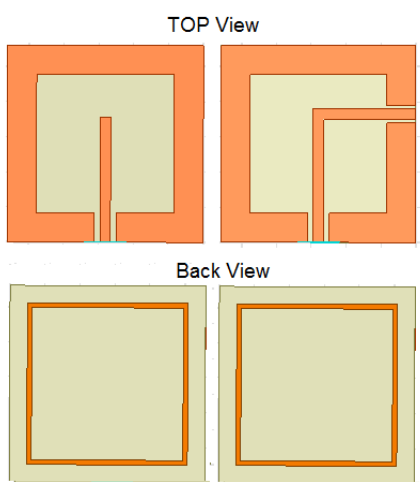

Ant II
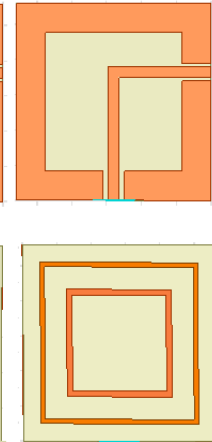

Ant IV
Fig 2. Four stages of proposed antenna design.

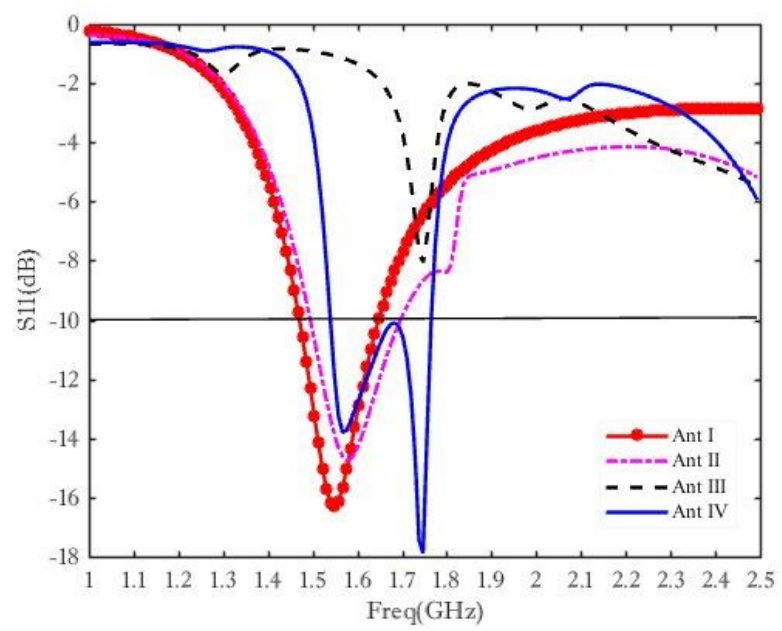

Fig 3. Simulated return loss of four proposed GPS antenna

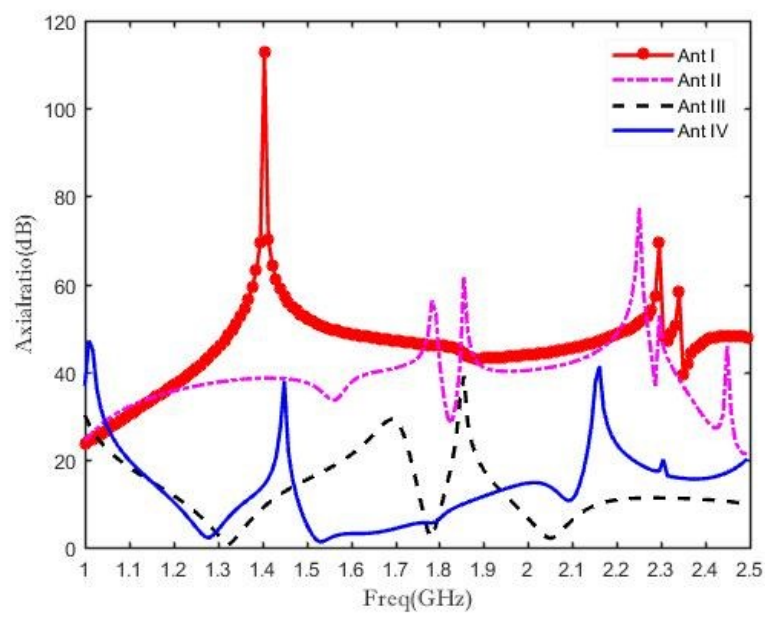

(a) 


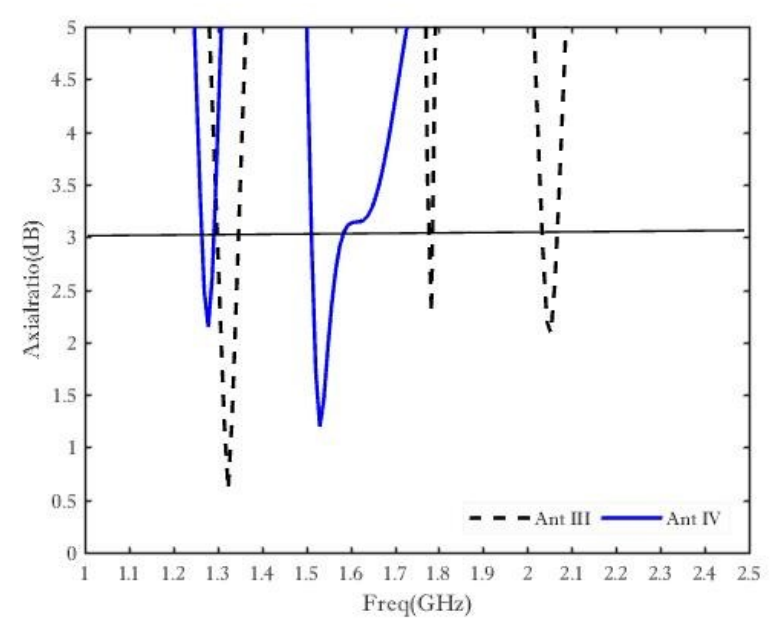

(b)

Fig 4. Simulated (a) AR for four proposed CPS antenna and (b) AR for antenna IV

Fig.5, shows the simulated radiation pattern at GPS frequency in E-plane (XZ: $\varphi=0)$ and H-plane (YZ: $\varphi=90)$.

Fig.6, displayed desirable bidirectional characteristics at $1.57 \mathrm{GHz}$. Regarding Fig.6, it can be seen that the antenna structure produces right-hand circularly polarized (RHCP) radiation along the back side of the proposed antenna ( $Z$ orientation) and left-hand circularly polarized (LHCP) along the front side of the antenna ( $+\mathrm{Z}$ orientation). The obtained gain in the $\mathrm{CP}$ bandwidth range varies from $-6.7 \mathrm{~dB}$ in the lower band to $-3.3 \mathrm{~dB}$ in the higher band. In Fig.7, the simulated antenna possesses $-3.9 \mathrm{~dB}$ gain for $1.57 \mathrm{GHz}$ in the $\mathrm{CP}$ bandwidth range. The negative gain in $\mathrm{dB}$ means that the nominal gain is less than 1 , but the signal strength received from GPS transmitter is high, therefore, the antenna can detect the message signal come from the GPS transmitter even if negative gain.

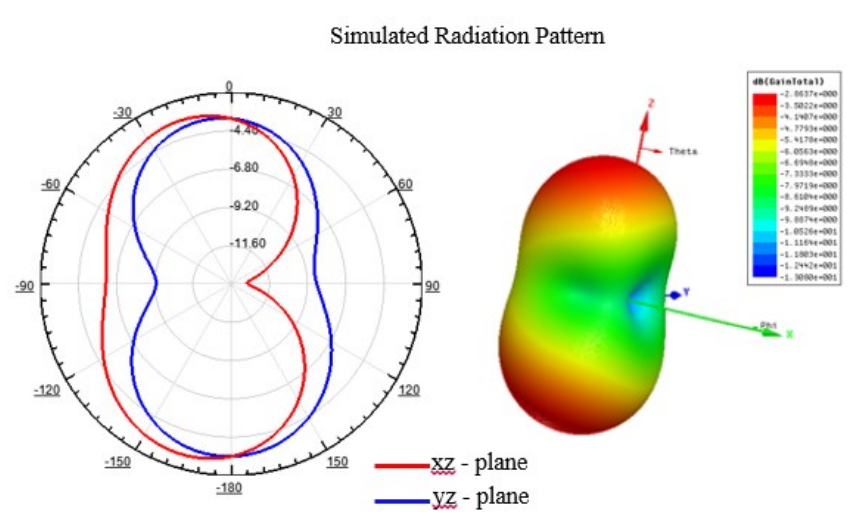

Fig 5. 3D and 2D simulated radiation patterns in E plane and $\mathrm{H}$ plane at $1.57 \mathrm{GHz}$
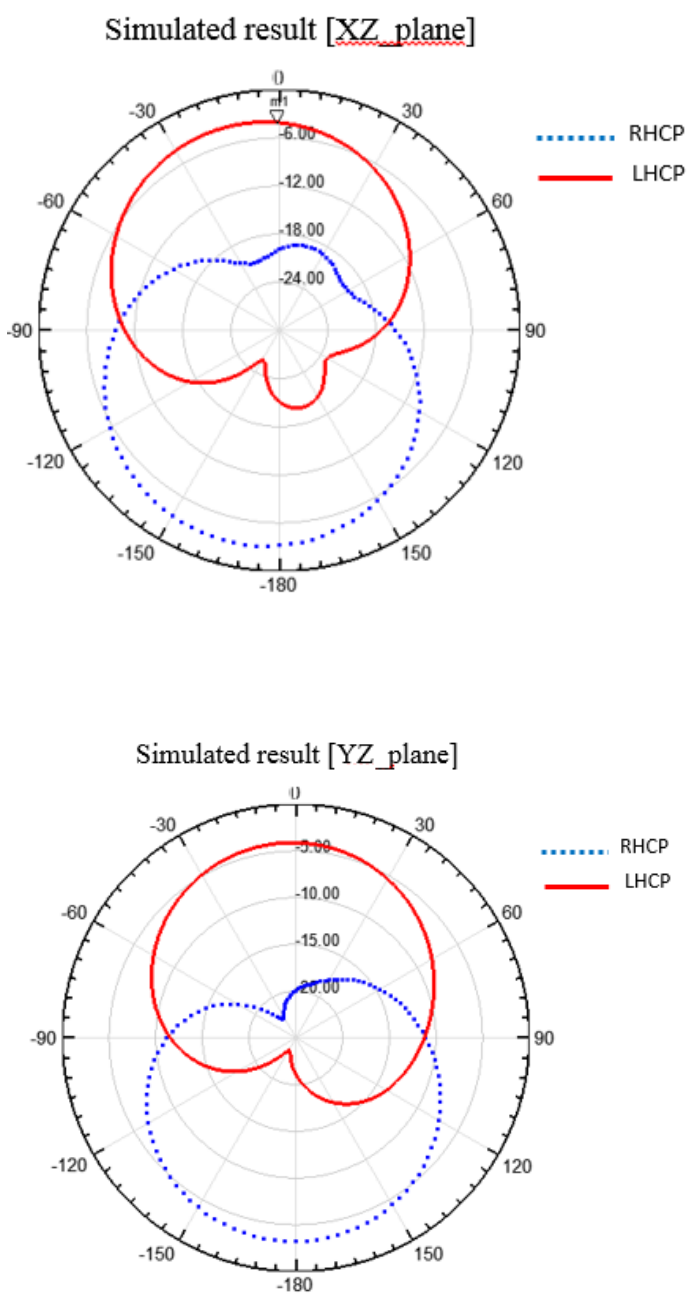

Fig 6. Simulated LHCP and RHCP radiation patterns of the proposed antenna at $1.57 \mathrm{GHz}$

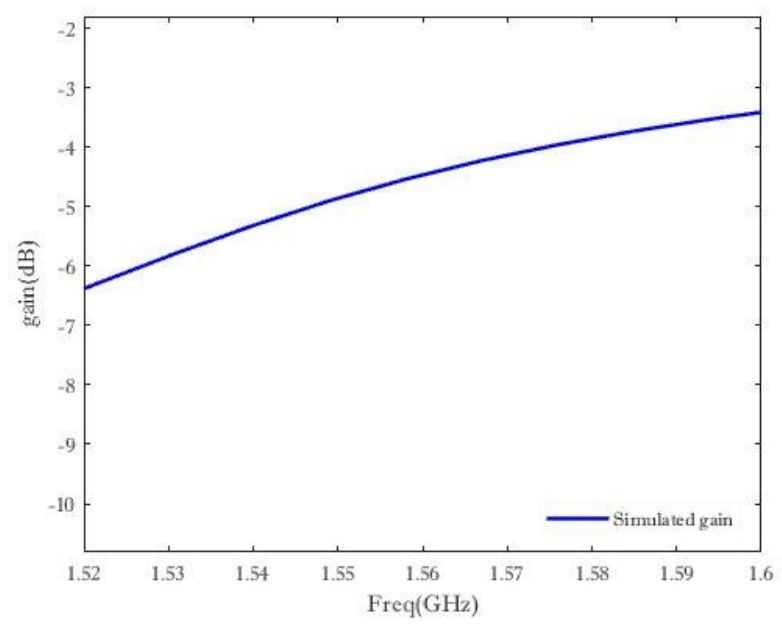

Fig 7. Simulated Gain of proposed antenna 


\section{CONCLUSION}

In this study, the design of a square slot antenna with circular polarization and coplanar waveguide (CPW) with the size of $56 \times 56 \mathrm{~mm}^{2}$ was demonstrated. An L-shaped feed strip induced the circular polarization characteristics and $3 \mathrm{~dB}$ ARBW. The desirable impedance matching $\left(\mathrm{S}_{11}<\right.$ $-10 \mathrm{~dB}$ in reflection coefficient) and the $3 \mathrm{~dB}$ ARBW from 1.525 to $1.6 \mathrm{GHz}$ can be achieved for center frequency of

1.57 GHz. The simulated radiation pattern exhibits a bidirectional pattern. Therefore, the proposed antenna is compatible with GPS applications.

\section{REFERENCES}

[1] Bukhori, M.F., et al, "Design of microstrip antenna for GPS application," in RF and Microwave Conference, 2008. RFM 2008. IEEE International. 2008. IEEE.

[2] Row, J.-S., "Design of square-ring microstrip antenna for circular polarization," Electronics Letters, 2004. 40(2): p. 9395.

[3] Golazari, S.S., et al. , "Multiband low profile printed monopole antenna for future $5 \mathrm{G}$ wireless application with DGS," in Knowledge-Based Engineering and Innovation (KBEI), 2017 IEEE 4th International Conference on. 2017. IEEE.

[4] Neda Rojhani, et al, "A Compact TEM Horn Antenna for Ground Penetrating Radar" IEEE International Conference on Advances in Computing, Communications \& Informatics 2018.

[5] S. S. Golazari, N. Amiri and F. H. Kashani, "Design, simulation and measurement of loop plasma antenna in UHF band," 2016 24th Telecommunications Forum (TELFOR), Belgrade, 2016, pp. 1-4

[6] Chi, L.-P., et al, "A circularly polarized CPW-fed square slot antenna with embedded Hilbert-curves and rectangular patches for GPS/GLONASS operations," in Cross Strait Quad-Regional Radio Science and Wireless Technology Conference (CSQRWC), 2013. 2013. IEEE.

[7] Lai, J.-Y., et al, "A wideband CPW-fed monopole antenna with linear and circular polarizations," in Antennas and Propagation \& USNC/URSI National Radio Science Meeting, 2017 IEEE International Symposium on. 2017. IEEE.

[8] Chen, H.-M., et al. , "Microstrip-fed circularly polarized square-ring patch antenna for GPS applications," IEEE Transactions on Antennas and Propagation, 2009. 57(4): p. 1264-1267.

[9] Chufarov, M., "Double-band circularly-polarized antenna for Glonass-GPS applications," in EUROCON 2009, EUROCON'09. IEEE. 2009. IEEE.

[10] Wang, Y., et al. ., "A dual-band circularly polarized stacked microstrip antenna with single-fed for GPS applications," in Antennas, Propagation and EM Theory, 2008. ISAPE 2008. 8th International Symposium on. 2008. IEEE.

[11] Pozar, D.M. and S.M. Duffy., "A dual-band circularly polarized aperture-coupled stacked microstrip antenna for global positioning satellite," IEEE Transactions on Antennas and Propagation, 1997. 45(11): p. 1618-1625.

[12] Chen, S., et al., "Compact dual-band GPS microstrip antenna using multilayer LTCC substrate,"IEEE Antennas and Wireless Propagation Letters, 2010. 9: p. 421-423. 